\title{
Leaders in focus: generational differences from a personality-centric perspective
}

\author{
Mădălina BĂLAN* \\ HART Consulting, Bucharest, Romania
}

Silvia MARIN

HART Consulting, Bucharest, Romania

Andreea MITAN

National University of Political Studies and Public Administration, Bucharest, Romania

Florina PÎNZARU

National University of Political Studies and Public Administration, Bucharest, Romania

Elena-Mădălina VĂTĂMĂNESCU

National University of Political Studies and Public Administration, Bucharest, Romania madalina.vatamanescu@facultateademanagement.ro

\begin{abstract}
Alexandra ZBUCHEA
National University of Political Studies and Public Administration, Bucharest, Romania
\end{abstract}

\begin{abstract}
The generational differences among leaders have progressively captured the attention of both researchers and practitioners interested in their dynamics within the work environment. Many analyses in this respect have been focused on the differences between Millennials (Generation Y) and Generation $X$ members from a personality-centric perspective, the great majority of the examinations revolving around Western research samples. By acknowledging the current state and assuming the calls for further investigations advanced by various researchers, this conceptual and empirical undertaking aims to provide an exploratory outlook on generational differences among Romanian leaders, by employing worldwide reputed research instruments such as the Hogan Personality Inventory (HPI), Hogan Development Survey (HDS) and Motives, Values, Preferences Inventory (MVPI). A sample of over 700 subjects was considered in the running of the statistical analyses, thus allowing to draw pertinent conclusions apposite to the envisaged population. Even though statistically significant findings were retrieved on few scales pertaining to the three applied instruments, one key insight advanced by the present endeavor resides in the extension of the scope of the existing literature dedicated to the generational differences from a leadership perspective via the integration of an Eastern European landscape which adds to the evidence in the field and opens up new research challenges for complementary scrutiny.
\end{abstract}

Keywords: leadership, generational differences, Generation Y, Generation X, Motives, Values.

\footnotetext{
${ }^{*}$ Authors are mentioned in alphabetical order
}

DOI: $10.2478 / m m c k s-2019-0026$ 


\section{Introduction}

From a bird's eye view, each new generation faces different experiences regarding education, political events and social milestones, is dared by different economic situations, and meets a different stage of technological development. These factors could lead people of various ages to have differing work preferences and approaches, thus raising questions regarding their dynamics in the work environment and their specificities and standpoints on various leadership styles.

At present, four generations are still active in the workforce; however, by 2025, it is believed that more than $75 \%$ of the workforce worldwide will belong to the generation of Millennials (E\&Y, 2014). Even though this group of people developed their worldview in a particularly fast-paced technological environment, growing up connected to walkie-talkies, mobile phones, PCs and later laptops, tablets and smartphones, Millennials (i.e., Generation Y)are deemed to have surprisingly traditional desires and expectations from their employers: more than $80 \%$ of the Millennials in US and almost $70 \%$ of the ones in UK, Germany and China seek security and stability at work (Allianz, 2017). In comparison to more mature workers, they are more distrustful of institutions, tend to marry later in life than their parents, are not eager to own a house or cannot afford to buy one (only about $40 \%$ of Millennials own the house they live in, as compared to $64 \%$ of Gen X-ers at their age), are reluctant to start a business, especially as they faced numerous crises growing up (E\&Y, 2018).

The more mature Gen X-ers seem to be searching for work-life balance, preferred early life „portfolio” careers, are loyal to their profession, not to their employer, while Generation Y members seek freedom and flexibility, they work with companies, not for companies, and Generation Z members (born after 1995) seek security and stability, and are career multitaskers (will move from a company to another and will work for „pop-up” businesses) (Barclay, 2013). It is also contended that Gen X-ers enjoy receiving incentives for their good work (Levin, 2001), but would not demand recognition for their results (Niemiec, 2000).

Within the framework of a many-colored description, a proper investigation of generational issues comes forward as a natural step all the more so as Millennials are an increasingly more important workforce, both in terms of number and their status as the next cohort of leaders. The empirical reality is also supported by a growing body of studies devoted to capturing the multifaceted dimensions of the trend (Fore, 2013; Medyanik, 2016; Bartels II, 2017; Churchill, 2018; Do, Van Nguyen, \& Dinh, 2018). In this vein, the aspects that are connected to Millennial leaders are trial and error approach, need for mentors, new approaches of teamwork and requirements among peers, an attachment to life-work balance.

Nevertheless, these analyses are rather limited in terms of the complexity of the research and domain-focus, basically lacking a thorough outlook on leadership differences among generations, especially with a focus on personality traits. Both deeper and wider investigations in the field are welcome with a view to clarify the underlying factors mainstreaming the specificity of each generation and, in this sense, resorting to welldefined methodological designs based on worldwide reputed instruments such as the Hogan Personality Inventory (HPI), Hogan Development Survey (HDS) and Motives, Values, Preferences Inventory (MVPI) is liable to support the exploratory endeavor. 
Conflating the aforementioned considerations, the paper was structured as follows: the first section is dedicated to the presentation of the conceptual background of the study, whereas the second one describes the research design and methodology; the third section concentrates itself on the findings and discussion of the results derived from the investigation of a large sample of over 700 Romanian leaders activating in different corporations. The paper ends with the conclusions section which sums up the main arguments supported in the study.

\section{Conceptual background}

Leaders and leadership are topics relevant both for academia and practitioners. Leadership means the ability to build and maintain high-performing teams. As Hogan and Kaiser (2005) pointed out, leadership depends on the personality of the leader. The leader and his/her characteristics would impose not only a certain leadership style, but also would influence the effectiveness of an organization by means of task allocation, relations development, change management, and behavior (Yukl, 2012). Therefore, in a business logic, understanding leadership and its correlations with the personality and behavioral traits springs as a relevant issue.

In its own right, personality is a complex concept, investigated by many scientific disciplines, and considered both from an inner and an outer perspective (Hogan \& Kaiser, 2005, pp.170-171). It is also an appealing topic for researchers interested to profile various generations. In this vein, there is a relatively wide corpus of studies scrutinizing the profiles of the members of Generations X and Y. Various contributions present the Millennials as feeling themselves special and confident, as being both team-oriented and achievers, as optimistic, extroverts and narcissistic, having unrealistic expectations and high levels of entitlement (Howe \& Strauss, 2007; Thompson \& Gregory, 2012; Twenge, 2012; Twenge \& Campbell, 2012). These characteristics might prove to be beneficial not only for the organizations for which they work, but also for the wider society (Brant \& Castro, 2019). Despite some common perceptions, research shows that Millennials are work-oriented as much as older generations but are more flexible in changing their occupation (Pyöriä, Ojala, Saari, \& Järvinen, 2017). In this last regard, the career patterns are, nevertheless, not so different from older generations, pointing out that the generation gap in the work environment might not be as wide as generally considered (Culpin et al., 2015). All these aspects might make them flexible, determined, able to develop relationships intra- and inter-generations, as well as effective leaders.

In contrast, other studies contended that members of Generation $\mathrm{Y}$ are individualistic, narcissistic, and tend to dislike hierarchies (Twenge, 2009), or tolerant, interested in the general good, and that they behave like activists (Greenberg \& Weber, 2008), or they do not do as they are told, if they do not understand why (Castells \& Harding, 2007). As leaders, Generation $Y$ members have been presented as likely to face some challenges regarding emotional control, working with sustained energy, managing obstacles, losses and ambiguity, taking on responsibility, listening to others and their ideas, setting an agenda for the team, keeping an eye on priorities and paying attention to detail (Pînzaru et al., 2016).

In his endeavor to capture what Millennials across the world want from work, Bresman (2015) started his argumentation from a self-objectivizing reality, that is, more and more Millennials are occupying leadership positions worldwide and hence the direct 
interest of organizations is to support their work performance and efficiency. The author noticed that most studies on the topic are focused on specific populations and samples (typically Western) and that a comprehensive outlook is still embryonic. The situation is delicate to some extent as context-centric studies may be generalized under the pressure of pertinent information shortage, a fact which may be conducive to inadequate conclusions and to the operationalization of bad decisions at the organizational level. Moreover, revolving around limited samples may affect an up-to-date and relevant view on how to attract, retain, and develop Millennial leaders across the globe and may result in wasting highly-skilled human resources and business opportunities. In order to provide a more articulate picture, Bresman (2015) has illustrated the main reasons why Millennials want to be leaders by categorizing the subjects' responses according to regional affiliations (Figure 1). In this survey, a total sample of 16637 individuals aged between 18 and 30 were included, coming from 43 countries across Asia, Africa, Europe, Latin America, the Middle East, and North America.

\section{MILLENNIALS WANT TO BE LEADERS FOR DIFFERENT REASONS}

What is it you consider most attractive in a managerial/leadership role?

PERCENTAGE OF RESPONDENTS $60 \%-$
- High future earnings

Opportunities to influence the company/organization Working with strategic challenges Power to make decisions

- Challenging work

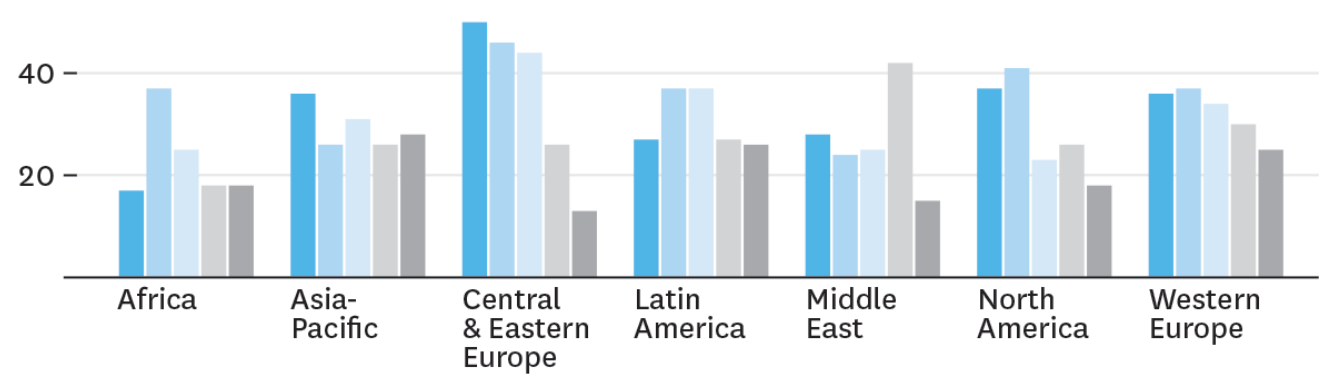

SOURCE "MILLENNIALS: UNDERSTANDING A MISUNDERSTOOD GENERATION"

HBR.ORG

Figure 1. Results of the survey regarding the reasons why Millennials want to be leaders Source: Bresman, 2015, p. 3.

As illustrated in the picture above, the range of responses is quite broad, therefore the discussion of the findings cannot offer generic insights for all the Millennial population; the only conclusion which might be rightly drawn from these distributions is that the cultural and national factors play an important role in the profiling of the young generation.

Placing the discussion in the framework of leadership ambitions, Bresman and Rao (2017) posited that there are not significant generational differences in this respect, the only variation which should be considered - as a relevant factor - is linked to the contextual differences, namely cross-country variations. This dispersion triggers implications for the employers and, consequently, the two researchers pointed out the following conclusions "Those in markets lacking enthusiasm for leadership, including Denmark, Sweden, and France, across which only $56 \%$ of Gen Y professionals said becoming a leader was 
important to them, will find their talent pipelines harder to fill; those in countries like Mexico, the U.S., and India will have to find ways to manage expectations and provide leadership experience or other motivation for ambitious workers" (Bresman \& Rao, 2017, p. 3).

In a more specific research, founded on Hogan Assessments, which covered a large multinational sample of 255,479 subjects, Foster and Meyer (2012) showed that there were significant differences on the Hedonism and Recognition scales (please see Table 1 for definitions of scales), Generation Y scoring higher than Generation X participants. Twenge and Campbell (2008) found that Millennials have higher self-esteem, are prone to anxiety and depression, and have a more external locus of control, but the study conducted by Wong et al. (2008) contradicts the existence of generational differences.

Further, a research conducted by Hogan Research Division (2014) on a large multinational sample of 1,127,389 subjects which was divided into four sub-samples corresponding to four generations (WWII generation, Baby Boomers, Generation X, and Generation Y) indicated that the scores for Sociability consistently increased from WWII generation to Millennials, but the same study infirmed the existence of significant differences among generations in terms of Ambition. Another study conducted by Hogan Research Division (2014) on a large multinational sample of 416,865 cases shows that for the Diligent scale, the average scores are lowest for Baby Boomers and highest for Generation $Y$, thus observing the increase of the scores along generations.

Nevertheless, researchers point out that their specificities require different leadership and managerial approaches, compared to previous generations (Anderson, Baur, Griffith, \& Buckley, 2017). At times, research is contradictory when comparing the Millennials with the older workforce (Lyons \& Kuron, 2014) and assumptions related to generational gaps or age differences are steadily challenged (Rudolph, Rauvola, \& Zacher, 2018).

Given the diverse findings of previous studies, a research gap emerges in that further analyses are needed in order to clarify (i.e., validate or not) the evidence as depicted in the literature. To provide a preliminary answer to this research problem, the current undertaking aims to test the existence of significant differences between generations from a personality-centric viewpoint, by employing well-reputed standardized instruments such as the Hogan Personality Inventory (HPI), the Hogan Development Survey (HDS), the Motives, Values, Preferences Inventory (MVPI). The research strategy hence envisages enhancing the knowledge on the topic via an exploratory endeavor meant to advance a phenomenological view, that is, a context-driven insight.

\section{Research Design and Methodology Hypotheses}

Based upon the considerations presented above, we formulated the following hypotheses:

H1: There are significant differences between generations (i.e., Generation Y and X) in terms of the scale comprised by Hogan Personality Inventory (HPI).

H2: There are significant differences between generations (i.e., Generation Y and X) in terms of the scale comprised by Hogan Development Survey (HDS).

H3: There are significant differences between generations (i.e., Generation Y and X) in terms of the scale comprised by Motives, Values, Preferences Inventory (MVPI). 


\section{Material and method}

\section{Participants}

For each of the instruments applied, a convenience sample of leaders (middle managers) was selected among individuals with higher education, working in the urban environment, in private companies, mostly Romanian corporations.

The samples were divided into categories, that is, members from Generation Y (1931 years old), respectively Generation X (32-55 years old), in accordance with Bresman and Rao's (2017, p. 2) classification - "Generation X, the age cohort born before the 1980s but after the Baby Boomers; Generation Y, or Millennials, typically thought of as those born between 1984 and 1996". The birth year was computed based on the gap between participants' self-reported age at the time of assessment and the assessment date.

In what concerns the application of the Hogan Personality Inventory (HPI), the sample consisted of 759 subjects (198 for Generation Y and 561 for Generation X). Further, a total of 593 participants (140 for Generation Y and 453 for Generation X)were involved in the research based on the Hogan Development Survey (HDS) whereas 576 subjects (133 for Generation Y and 443 for Generation X) agreed to participate in the investigation based on the Motives, Values, Preferences Inventory (MVPI).

\section{Procedure}

The research instruments were applied in accordance with the formal agreements signed between Hart Consulting (the Romanian company owning the rights for distributing Hogan Personality Assessments in Romania) and several corporations operating in Romania. Hogan Assessments personality inventories were applied online during several months. The collected data was further analyzed in terms of consistency and a final validation of the retrieved responses was performed (e.g., removing test cases and cases with missing assessment data or missing self-reported age).

In order to test the intergenerational differences (Generation X versus Generation $\mathrm{Y}$ ), T-test for Independent Samples was employed, an inferential statistical operation which determines whether there is a statistically significant difference between the means in two unrelated groups. In this sense, the IBM SPSS Statistics 20 was used to conduct the analysis.

\section{Measures}

As previously pointed out, the empirical investigation relied on psychological testing using Hogan assessment tools which integrate a multi-dimensional approach of the personality targeting three key areas: individual values, strengths, and risks. The obtained scores are objectivized into percentiles, allowing the comparison between average scale scores.

The first research instrument - Hogan Personality Inventory (HPI) - assesses personality and predicts performances via seven different dimensions. Its scales and short definitions are presented in Table 1.

Table 1. HPI scales and definitions

\begin{tabular}{|l|l|}
\hline HPI Scale & Measures the degree to which a person seems... \\
\hline Adjustment & Calm and self-accepting or self-critical and tense \\
\hline Ambition & Socially self-confident, leader-like, competitive, and energetic \\
\hline Sociability & Comfortable interacting with others \\
\hline Interpersonal Sensitivity & Perceptive, tactful, and socially sensitive \\
\hline Prudence & Conscientious, conforming, and dependable \\
\hline
\end{tabular}




\begin{tabular}{|l|l|}
\hline Inquisitive & Bright, creative, and interested in intellectual matters \\
\hline Learning Approach & Comfortable with academic activities and education for its own sake \\
\hline
\end{tabular}

The second research instrument - the Hogan Development Survey (HDS) - is the first assessment tool meant to measure personality characteristics conducive to job derailment. All the eleven scales pertaining to the HDS appraise the behavioral tendencies liable to impede work relationships, hence afflicting productivity, or negatively influencing overall career potential (Table 2). Both the HPI and the HDS have demonstrated good psychometric properties over time.

Table 2. HDS scales and definitions

\begin{tabular}{|l|l|}
\hline HDS Scale & Measures the degree to which a person seems... \\
\hline Excitable & $\begin{array}{l}\text { Moody and inconsistent, being enthusiastic about new persons or projects and then } \\
\text { becoming disappointed with them. }\end{array}$ \\
\hline Skeptical & Cynical, distrustful, sensitive to criticism, and questioning others' intentions. \\
\hline Cautious & Resistant to change and reluctant to take chances for fear of being criticized. \\
\hline Reserved & Socially withdrawn and lacking interest in or awareness of the feelings of others. \\
\hline Leisurely & Autonomous, indifferent to others' requests, and irritable when they persist. \\
\hline Bold & $\begin{array}{l}\text { Unusually self-confident and unwilling to admit mistakes, listen to advice, or learn from } \\
\text { experience. }\end{array}$ \\
\hline Mischievous & To enjoy taking risks and testing the limits. \\
\hline Colorful & Expressive, dramatic, and wanting to be noticed. \\
\hline Imaginative & To act and think in creative and sometimes unusual ways. \\
\hline Diligent & Careful, precise, and critical of the performance of others. \\
\hline Dutiful & Eager to please, reliant on others, and reluctant to take independent action. \\
\hline
\end{tabular}

The third instrument -the Motives, Values, Preferences Inventory (MVPI) - measures areas that are expected to motivate people at work. Based on self-report measures, the MVPI has also proved good psychometric properties over time, its 10 primary scales providing a compelling framework for assessing multifold individual drivers, as illustrated in Table 3.

Table 3. MVPI scales and definitions

\begin{tabular}{|l|l|}
\hline MVPI scales & Measures \\
\hline Aesthetics & Valorization of creative and artistic self-expression \\
\hline Affiliation & Valorization of frequent and varied social interaction \\
\hline Altruistic & Valorization of actively helping others and improving society \\
\hline Commerce & Valorization of business activities, money, and financial gain \\
\hline Hedonism & Valorization of fun, good company, and good times \\
\hline Power & Valorization of competition, achievement, and being influential \\
\hline Recognition & Valorization of fame, visibility, and publicity \\
\hline Science & Valorization of ideas, technology, and rational problem solving \\
\hline Security & Valorization of certainty, predictability, and risk-free environments \\
\hline Tradition & Valorization of history, rituals, and old-fashioned virtues \\
\hline
\end{tabular}

Source: adapted from Foster \& Meyer, 2012, p. 3. 


\section{Findings and discussion}

The testing of the first research hypothesis - H1: There are significant differences among generations (i.e., Generation $\mathrm{Y}$ and $\mathrm{X}$ ) in terms of the scale comprised by Hogan Personality Inventory (HPI) - revolved around the statistically significant generational differences on the seven scales comprised by the assessment tool. A total of 759 cases (198 for Generation Y and 561 for Generation X) of complete HPI data were compiled within the framework of the current research. The average scores retrieved by each generation on each scale are presented in Figure 2.

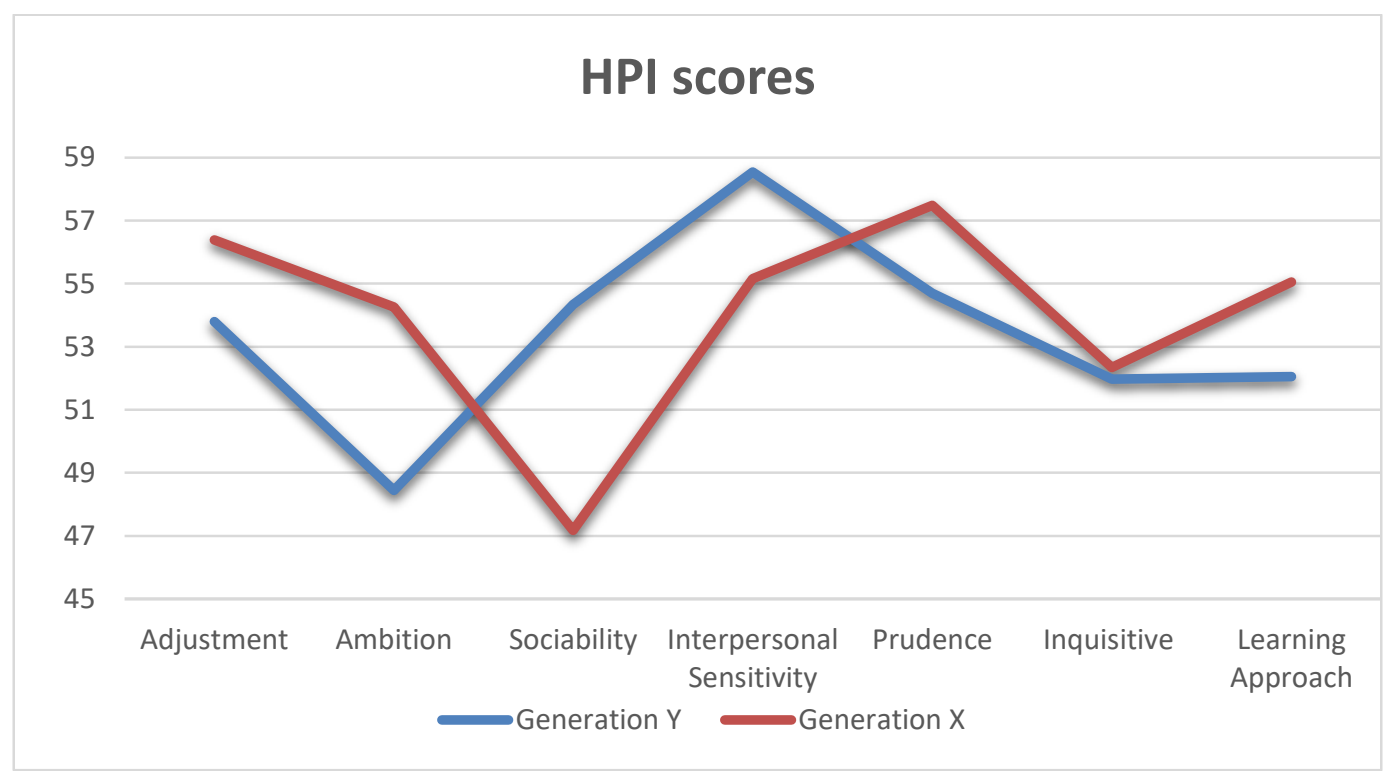

Figure 2. Average HPI scores for the two generations

Source: Authors' own research.

The application of the Independent Samples T Test with a view to depict significant generational differences brought only two scales to the fore, namely Ambition $\operatorname{t}(757)=-$ $2.276, \mathrm{p}<.05)$ and Sociability $(\mathrm{t}(757)=2.915, \mathrm{p}<.01)$. For the rest of the scales, Sig. (2tailed) $>.05$, thus positing that the differences in average scores have no statistical meaning.

The examination of the average scores obtained by each generation on each of the two scales - i.e., Ambition - Generation Y $(M=48.44, S D=30.59)$ versus Generation X $(M=54.26, S D=31)$, respectively Sociability - Generation $Y(M=54.34, S D=29.13)$ versus Generation $X(M=47.18, S D=29.92)$ - revealed that the younger generation of leaders are less ambitious than their counterparts and, inherently, that members from Generation X are more socially self-confident, leader-like, competitive, and energetic, displaying a higher degree of assertiveness and self-initiation. Nevertheless, Generation Y individuals seem more comfortable interacting with others, more outgoing and prone to be perceived as attention-seeking in certain situations. They exhibit a higher level of proactiveness than their older colleagues who are often more socially reactive.

The findings are partially consistent with a previous study conducted by Hogan Research Division (2014) on a large multinational sample of 1,127,389 subjects which was divided into four sub-samples corresponding to four generations (WWII generation, Baby Boomers, Generation X, and Millennials / Generation Y). The research showed that the 
scores for Sociability consistently increased from WWII generation to Millennials, thus supporting the current findings. However, the same study infirmed the existence of significant differences among generations in terms of Ambition.

Focusing on the second research hypothesis - H2: There are significant differences among generations (i.e., Generation $\mathrm{Y}$ and $\mathrm{X}$ ) in terms of the scale comprised by Hogan Development Survey (HDS) - the average scores of eleven scales were considered. In this front, 593 cases of complete HDS data (140 for Generation Y and 453 for Generation X) were compiled. Figure 3 presents the average scores for HDS scales within a twofold generational approach.

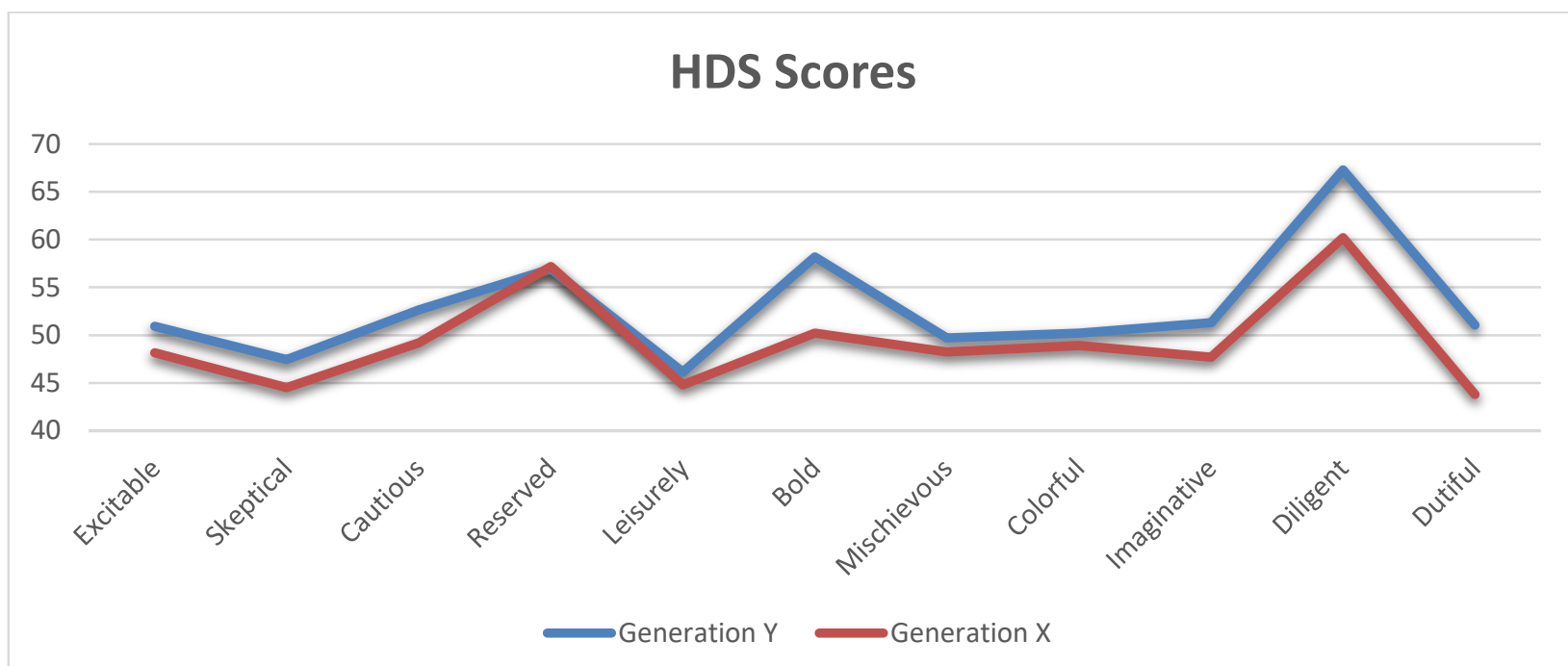

Figure 3. Average HDS scores for the two generations

Source: Authors' own research.

The Independent Samples T Test running revealed that only three out of the eleven HDS scales indicated statistically meaningful differences between Generation $\mathrm{Y}$ and X. These scales are Bold $(\mathrm{t}(591)=2.552, \mathrm{p}<.05)$, Diligent $(\mathrm{t}(255.939)=2.463, \mathrm{p}<.05)$ and Dutiful $(\mathrm{t}(207.186)=2.433, \mathrm{p}<.05)$. Looking into the scores apposite to each generation - Bold Generation Y $(M=58.19, S D=31.76)$ versus Generation X $(M=50.23, S D=32.41)$, Diligent Generation $Y(M=67.32, S D=28.94)$ versus Generation $X(M=60.22, S D=32.43)$ and Dutiful Generation $Y(M=51.05, S D=31.71)$ versus Generation $X(M=43.81, S D=27.41)$-several insights should be put forward. Firstly, the leaders from Generation Y are more unusually self-confident and unwilling to admit mistakes, listen to advice, or learn from experience than their older counterparts. Sometimes, they may seem exceptionally self-promoting and smug, fact which may trigger unpleasant situations at work. Secondly, they seem more careful, precise, and critical of the performance of others, displaying a higher tendency towards micromanagement than Generation X members. Thirdly, they are more eager to please, reliant on others, and reluctant to take independent action, showing a higher propensity towards ingratiating themselves with their work peers.

These findings are partially consistent with the results concluded by Hogan Research Division (2014) which conducted a research on a large multinational sample of 416,865 cases. For the Diligent scale, the study contended that the average scores are lowest 
for Baby Boomers and highest for Generation Y, thus admitting the increase of the scores along generations.

In order to test the third hypothesis - H3: There are significant differences among generations (i.e., Generation $\mathrm{Y}$ and $\mathrm{X}$ ) in terms of the scales comprised by Motives, Values, Preferences Inventory (MVPI) - we conducted the Independent Samples $\mathrm{T}$ Test to determine the impact of generational membership on results for MVPI scales. In this vein, the application of the instrument reached 576 subjects (133 for Generation Y and 443 for Generation X). The average scores are illustrated in Figure 4.

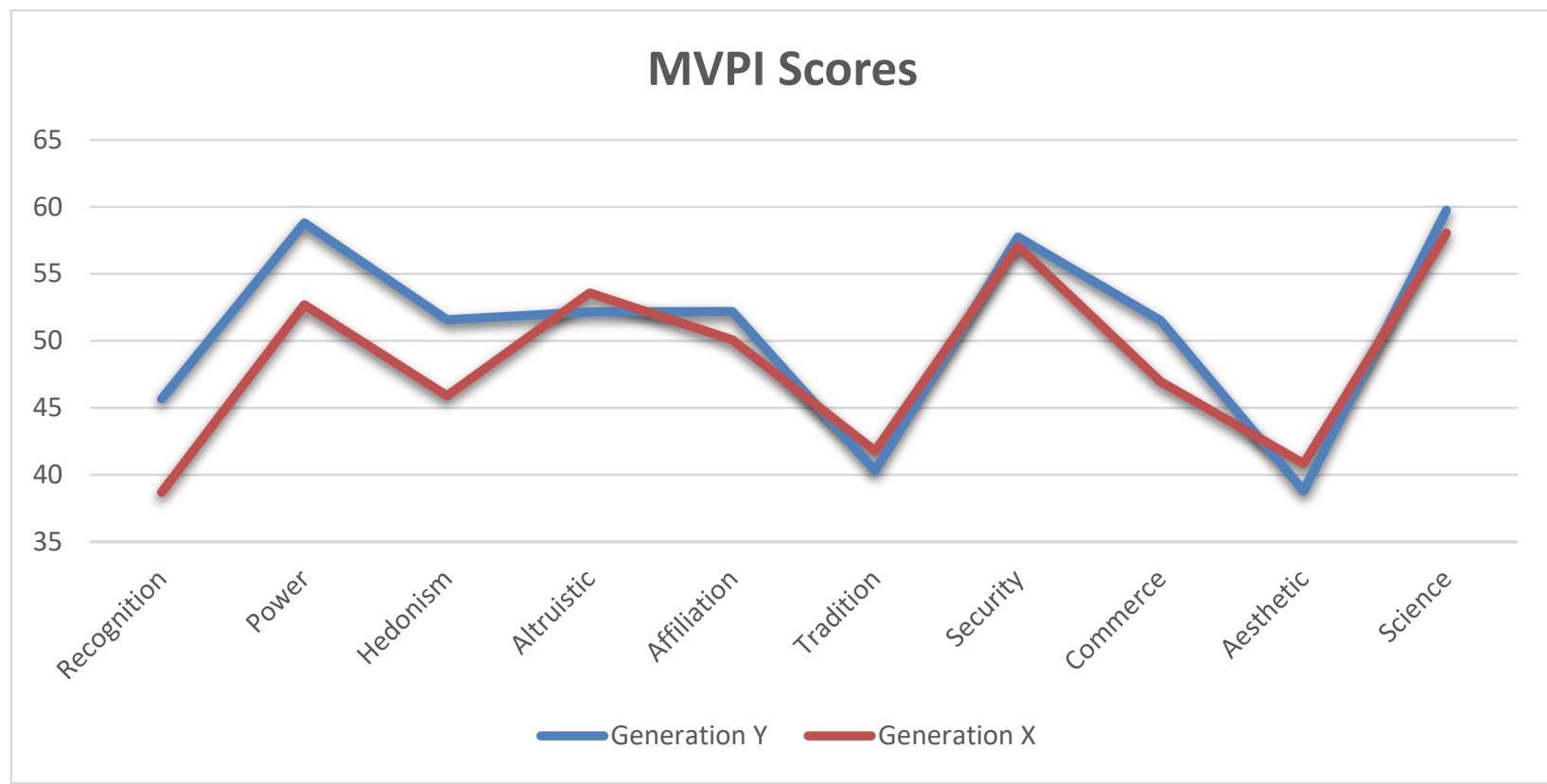

Figure 4. Average MVPI scores for the two generations

Source: Authors' own research.

When examining group statistics, three scales out of ten pointed to significant differences between generations, namely Recognition $(\mathrm{t}(574)=2.509, \mathrm{p}<.05)$, Power $(\mathrm{t}(574)=2.270, \mathrm{p}<.05)$ and Hedonism $(\mathrm{t}(574)=2.027, \mathrm{p}<.05)$. Analyzing the scores retrieved by each generation on the statistically significant factors - Recognition - Generation Y $(M=45.65, S D=27.53)$ versus Generation $X(M=38.68, S D=28.72)$, Power - Generation $Y$ $(\mathrm{M}=58.80, \mathrm{SD}=26.34)$ versus Generation $\mathrm{X}(\mathrm{M}=52.70, \mathrm{SD}=27.14)$ and Hedonism Generation $Y(M=51.56, S D=27.39)$ versus Generation $X(M=45.89, S D=28.54)$ - shed light on several aspects. On the one hand, Generation Y members value fame, visibility, and public acknowledgement more than their counterparts and, simultaneously, they lay emphasis on competition, achievement, and being in charge and perceived as influential. On the other hand, they strive for fun, good company, and good times, preferring lighthearted and open-minded work environments more than Generation X members.

The evidence brought forward by the current investigation is majorly in line with a previous study conducted by Foster and Meyer (2012) on a large multinational sample of 255479 subjects. Their analysis indicated significant differences on the Hedonism and Recognition scales, Generation Y scoring higher than Generation X participants. 


\section{Conclusions and future research directions}

The investigation of the three research hypotheses underscored that only some scales of the assessment tools indicated meaningful differences between the two generational groups, that is, Generations $\mathrm{Y}$ and X. At this level, it may be concluded that the impact of generational membership on the results is limited, therefore the hypotheses are partially supported.

Nevertheless, one key insight advanced by the current endeavor resides in the extension of the scope of the existing literature dedicated to the generational differences from a leadership perspective. In this way, the study answered the previous calls of various researchers which pointed to the imperative to develop more analyses on diverse countries and samples (implicitly, underlining that the analyses on Western samples are predominant). Even though most of the present findings are descriptive of previous evidence brought forward by studies conducted on large multinational samples (some of them covering four generational categories, thus having a broader scope), the integration of an Eastern European landscape adds to the evidence in the field. Here, future studies on the topic may benefit from the consideration of a more thorough delimitation across generations at work, discussing differences and variations in depth. This situation would allow for more statistical tests to be run, availing further compelling insights.

Another area which may be considered by future research refers to the extension of samples to other countries in order to facilitate comparisons among different cultures and to account for both generational and cultural differences. A proper operationalization of such goal would result in the emergence of a more specific scrutiny which is liable to provide decisionmakers with the adequate tools for improving their recruitment, selection, and retaining strategies and policies, making the most of the highly-skilled human capital and of the overall environmental opportunities.

Additionally, the particularization of the investigations on certain types of corporations (e.g., operating in specific sectors) would support the unfolding of inter- or cross-sector discussions, rounding off the leadership profiles of members from both generations. Here, a thorough examination of specificities would facilitate a better targeting of the right individual for the right position, hence allowing a more refined profiling for a certain leadership position. Well-validated and predictive personality assessments can be used to identify leadership potential or to help develop leaders by identifying their strengths and developmental needs.

\section{Acknowledgements}

For this work, the authors from the Faculty of Management (SNSPA) were supported by a grant of the Ministry of Research and Innovation, CNCS - UEFISCDI, project number PN-IIIP1-1.1-TE-2016-0232, within PNCDI III. 


\section{References}

Allianz (2017). Millennials: Work, Life and Satisfaction. Retrieved from https://www.allianz.com/content/dam/onemarketing/azcom/Allianz_com/press/d ocument/Allianz_Millennial_Survey.pdf.

Anderson, H.J., Baur, J.E., Griffith, J.A., \& Buckley, M.R. (2017). What works for you may not work for (Gen) Me: Limitations of present leadership theories for the new generation. Leadership Quarterly, 28(1), 245-260.

Barclays (2013). A Summary of Talking About My Generation: Exploring the Benefits Engagement Challenge. Retrieved from http://www.mas.org.uk/uploads/artlib/talking-about-my-generation-exploringthe-benefits-engagement-challenge.pdf.

Bartels II, W.L. (2017). Millennial's Perspectives on Pursuing Senior Leadership Positions: A Qualitative Study. Doctoral dissertation, Northcentral University, San Diego, California.

Brant, K.K., \& Castro, S.L. (2019). You can't ignore millennials: Needed changes and a new way forward in entitlement research. Human Resource Management Journal, 1-12. https://doi.org/10.1111/1748-8583.

Bresman, H. (2015). What Millennials Want from Work, Charted Across the World. Harvard Business Review, February 23, 2015. Retrieved from https://hbr.org/2015/02/whatmillennials-want-from-work-charted-across-theworld?referral=03759\&cm_vc=rr_item_page.bottom.

Bresman, H., \&. Rao, V.D. (2017). A Survey of 19 Countries Shows How Generations X, Y, and Z Are - and Aren't - Different. Harvard Business Review, August 1-6, 2017. Retrieved from https://hbr.org/2017/08/a-survey-of-19-countries-shows-howgenerations-x-y-and-z-are-and-arent-different.

Cassells, R., \& Harding, A. (2007). Generation whY? AMP.NATSEM Income and Wealth Report $17 . \quad$ Retrieved from http://www.natsem.canberra.edu.au/publications/?publication=ampnatsemincome-and-wealth-report-17-generation-why

Churchill, G.D. (2018). Millennials' Lived Work Experiences during the Shaping of Their Leadership Style: A Qualitative Phenomenological Study. Doctoral dissertation, Grand Canyon University. Retrieved from https://pqdtopen.proquest.com/doc/2150519841.html?FMT=ABS.

Culpin, V., Millar, C., Peters, K., Lyons, S.T., Schweitzer, L., \& Ng, E.S. (2015). How have careers changed? An investigation of changing career patterns across four generations. Journal of Managerial Psychology,30(1), 8-21.

Do, N.T.H., Van Nguyen, P., \& Dinh, P.U. (2018). A Qualitative Study Regarding the Leadership Traits and Styles of the Millennial Generation in the Manufacturing Industry. International Journal of Engineering \& Technology, 7(3), 52-58.

Ernst \& Young (2014). The future of work is changing. Will your workforce be ready? Retrieved from https://www.ey.com/Publication/vwLUAssets/ey-the-future-ofwork-is-changing-will-your-workforce-be-ready/\$FILE/ey-the-future-of-work-ischanging-will-your-workforce-be-ready.pdf

Ernst \& Young (2018). The Millennial Economy 2018 Millennials are changing with the world around them. Retrieved from 
https://www.ey.com/Publication/vwLUAssets/EY-millennial-deck-10/\$FILE/EYmillennial-deck-10.pdf

Fore, C.W. (2013). Next generation leadership: Millennials as leaders. Doctoral dissertation, Capella University. Retrieved from https://search.proquest.com/openview/a9f9de94cedbe2d8619ff6106100c554/1?p q-origsite $=$ gscholar \&cbl $=18750 \&$ diss $=y$.

Foster, J., \& Meyer, K. (2012). Generational and Cultural effects on values using the MVPI. Paper presented at the 2012 SIOP Conference, Symposium conducted at the $27^{\text {th }}$ Annual Meeting of the Society for Industrial and Organizational Psychology, San Diego, CA.

Greenberg, E., \& Weber, K. (2008). Generation We. How Millennial Youth Are Taking Over America And Changing Our World Forever. Emeryville: Pachatusan.

Hogan Research Division (2014). Generational and Cultural Effects on Personality using the Hogan Personality Inventory and Hogan Development Survey. Hogan Assessment Systems. Retrieved from hoganassessments.com.

Hogan, R., \& Kaiser, R.B. (2005). What we know about leadership. Review of General Psychology, 9(2), 169-180.

Howe, N., \& Strauss, W. (2007). Millennials go to college: strategies for a new generation on campus. Great Falls: LifeCourse Associates.

Levin, M. (2001). Bridging the generation gap. Association management. 53(1).

Lyons, S., \& Kuron, L. (2014). Generational differences in the workplace: A review of the evidence and directions for future research. Journal of Organizational Behavior, 35(S1), S139-S157.

Medyanik, K.K. (2016). A Holistic, Qualitative Case Study Regarding the Leadership Traits and Styles of the Millennial Generation. Doctoral dissertation, Northcentral University, San Diego, California.

Niemiec, S. (2000). Finding common ground for all ages. Security distributing and marketing. $30(3), 81$.

Pînzaru, F., Vătămănescu, E.M., Mitan, A., Săvulescu, R., Vițelar, A., Noaghea, C., \& Bălan, M. (2016). Millennials at Work: Investigating the Specificity of Generation Y versus Other Generations. Management Dynamics in the Knowledge Economy, 4(2), 173-192.

Pyöriä, P., Ojala, S., Saari, T., \& Järvinen, K.M. (2017). The millennial generation: a new breed of labour? Sage Open, 7(1). Retrieved from https://journals.sagepub.com/doi/full/10.1177/2158244017697158.

Rudolph, C.W., Rauvola, R.S., \& Zacher, H. (2018). Leadership and generations at work: A critical review. Leadership Quarterly, 29(1), 44-57.

Thompson, C., \& Gregory, J. B. (2012). Managing millennials: A framework for improving attraction, motivation, and retention. The Psychologist Manager Journal, 15(4), 237246.

Twenge, J.M. (2012). Millennials: The greatest generation or the most Narcissistic?. The Atlantic, May 2 . 2 Retrieved http://www.theatlantic.com/national/archive/2012/05/millennials-the-greatestgeneration-or-the-most-narcissistic/256638/.

Twenge, J.M., \& Campbell, S.M. (2012). Who are the Millennials? Empirical evidence for generational differences in work values, attitudes and personality. In Ng, E., Lyons, S. 
T., \& Schweitzer, L. (eds.), Managing the new workforce: International perspectives on the millennial generation (pp.152-180). Cheltenham, UK: Edward Elgar Publishing.

Twenge, J. M., \& Campbell, S. M. (2008). Generational differences in psychological traits and their impact on the workplace. Journal of Managerial Psychology, 23, 862-877.

Twenge, J.M. (2009). Generational Changes and Their Impact in The Classroom: Teaching Generation Me. Medical Education, 43(5), 398-405.

Wong, M., Gardiner, E., Lang, W., \& Coulon, L. (2008). Generational differences in personality and motivation. Journal of Managerial Psychology, 23(8), 878-890.

Yukl, G. (2012). Effective leadership behavior: What we know and what questions need more attention. Academy of Management Perspectives, 26(4), 66-85. 